\title{
Judaísmo y judaísmos: una realidad plural y compleja ${ }^{1}$
}

\author{
Guadalupe SEIJAS DE LOS Ríos ZarzosA \\ Universidad Complutense de Madrid \\ ORCID: 0000-0003-3673-5060 \\ gseijas@filol.ucm.es
}

\section{RESUMEN}

En este artículo se presenta una visión panorámica de la situación actual del judaísmo así como de los principales problemas y desafíos que afronta en la actualidad. De manera especial se reflexiona sobre el concepto de identidad judía, pues son muchas y diferentes las respuestas a las preguntas ¿quién es judío? y ¿qué significa ser judío?

Palabras clave: judaísmo, judaísmos, judeidad, judaísmo secular, identidad, modernidad.

\section{Judaism and Judaisms: a plural and complex issue}

\begin{abstract}
This paper offers a comprehensive view of Judaism in our days and presents the main problems and challenges derived from the encounter between Judaism and Modernitiy. It reflects in particular the question about Jewish identity regarding the many and different answers to questions such as who is a Jew? and what is the meaning of being a Jew?
\end{abstract}

Keywords: Judaism, Judaisms, Jewishness, Secular Judaism, Identity, Modernity.

SUMARIO: 1. El contexto. 1.1. La demografía. 1.2. La Shoá. 1.3. La creación del estado de Israel. 2. La pluralidad religiosa. 2.1. La observancia religiosa. 2.2. El papel de la mujer. 3. Judaísmo secular o laico. 4. ¿Quién es judío? 5. Reflexiones finales. 6. Bibliografía.

FECHA DE RECEPCIÓN: 26 DE 05 DE 2015 FECHA DE ACEPTACIÓN: 16 DE 09 DE 2015

\footnotetext{
${ }^{1}$ Con motivo de los atentados contra el semanario satírico Charlie Hebdo y contra una sinagoga danesa a comienzos de 2015 el ICCRR organizó el seminario Tolerancia y diálogo interreligiosos. Homenaje universitario en memoria de los atentados de París y Copenhague coordinado por Nuria Martínez de Castilla el 27 de marzo. En él participé con una conferencia sobre judaísmo, que es el origen de este texto. La elaboración de este trabajo ha sido posible gracias a la financiación del Ministerio de Ciencia e Innovación (proyectos I+D: Análisis unificado de textos hebreos con ordenador, FFI2012-37226).
} 
Cuando los medios de comunicación muestran imágenes de judíos suelen aparecer hombres vestidos con tirabuzones, ropas oscuras y sombrero rezando ante el Muro de las lamentaciones en Jerusalén o manifestaciones de colonos fundamentalistas que defienden sus asentamientos apoyados en la lectura literal de determinados pasajes bíblicos. Transmiten, de esta manera, una visión distorsionada del judaísmo actual, porque muchos judíos no se identifican con las creencias ni con las actitudes de los ultraortodoxos ni de los colonos. No existe un único judaísmo. El título de este trabajo refleja a través de adjetivos dos cuestiones esenciales para entender las religiones en la actualidad. Plural como sinónimo de diversidad y de sensibilidades distintas; compleja porque las religiones no son estáticas, sino que evolucionan ante los cambios sociales y culturales que se producen en cada época. En la actualidad las religiones deben dar respuesta a los desafíos planteados por la modernidad y a la inevitable tensión entre mantenerse fiel a la tradición o amoldarse a los nuevos tiempos. Las respuestas que ofrecen son diversas, desde la adaptación e innovación -con la búsqueda de nuevos lenguajes y símbolos-, hasta el apego a la tradición e incluso el retorno hacia la observancia más estricta. Pero también hay que tener en cuenta la aparición de nuevas sensibilidades en las que la cultura y la tradición configuran la propia identidad quedando al margen la cuestión religiosa.

\section{EL CONTEXTO}

Algunos acontecimientos han sido cruciales en la evolución del judaísmo actual. Me limitaré a señalar algunos de los más importantes.

\subsection{LA DEMOGRAFÍA}

Tras la segunda guerra mundial, la distribución de la población judía ha cambiado de forma notable. Aunque Francia con 478.000 judíos y Reino Unido con 290.000 son importantes centros, el grueso reside fuera de Europa. Destacan las comunidades judías de Canadá, Argentina, Australia, Brasil y Sudáfrica si bien los dos focos principales, en los que se concentra el $82 \%$ de la población judía mundial, son el estado de Israel (5.680.400) y Estados Unidos de América (5.425.000)². Cada uno de ellos, sin embargo, presenta un perfil sociológico y religioso distinto. La diferencia más significativa es que mientras en Israel el judaísmo es la religión mayoritaria, en EEUU los judíos son una minoría.

\footnotetext{
${ }^{2}$ Según los datos aportados en DellaPergola 2013, la cifra total de judíos a comienzos de 2013 era de 13.854.800 judíos. De ellos, casi un millón y medio corresponde a Europa, casi seis millones doscientos mil a América del Norte (EUUU y Canadá) y otros seis millones a Israel, incluidos los judíos de Cisjordania.
} 
Según los datos que recoge el Atlas de las Religiones ${ }^{3}$, en Israel se distribuyen de la siguiente manera: el $17 \%$ se considera muy observante $\left(8 \%\right.$ haredim $^{4}$ y $9 \%$ ortodoxos), el 39\% conservadores (masortim ${ }^{5}$ ) -partidarios de conjugar judaísmo y modernidad- y el 44\% judíos laicos (hilonim) ${ }^{6}$. El judaísmo reformista apenas tiene seguidores en Israel. Una de los principales conflictos en el seno de la sociedad israelí es la polarización entre una religión conservadora (datiim) y el secularismo militante antirreligioso (hilonim). Y este conflicto es consecuencia de la constitución mixta actual, donde una democracia secular está condicionada por posturas e ideologías de marcado carácter religioso $^{7}$. Los datos ofrecidos en el CBS, Statisitcal Abstract of Israel 2014 ${ }^{8}$, en el apartado relativo a religiosidad elaborado sobre la población mayor de 20 años, mantiene porcentajes similares en lo que respecta a judíos religiosos y a judíos seculares, aunque presenta ligeras variantes en la distribución de los distintos grupos de judíos religiosos: $36,2 \%$ conservadores (masortim) y los muy observantes alcanzan el $20,3 \%$, que corresponde a la suma de religiosos (datiim) con 9,9\% y ultraortodoxos (haredim) con $9.4 \%$. Este documento incluye además otra clasificación basada en la propia percepción del individuo frente al hecho religioso. Así, los no religiosos (ateos, agnósticos) suponen el 18,4\%, los no demasiado religiosos (creyentes no practicantes e indiferentes), el 25,6\%, los religiosos, $47,3 \%$ y los muy religiosos el $8.5 \%{ }^{9}$.

En los Estados Unidos de América la mayoría de los judíos se consideran religiosos con un $70 \%$ frente al $20 \%$ que se define como judío secular. Los reformistas son la sinagoga que cuenta con más adeptos con un $35 \%$, seguido de los conservadores con $26 \%$. Los ortodoxos cuentan con un número muy reducido de seguidores $(10 \%)$. Si el judaísmo secular es significativamente menor que en Israel, en cambio, son mayoría los partidarios de adaptar la religión judía al mundo moderno (61\%).

Otro hecho determinante corresponde a la nacionalidad. Todo judío, por el hecho de serlo, tiene asegurada la nacionalidad israelí (Ley de Retorno), independientemente de su lugar de nacimiento; mientras que en los EEUU los judíos son ciudadanos americanos. La inmensa mayoría ha nacido en este país y más de la mitad no tiene

${ }^{3}$ Denis, Fachon 2010, 39.

${ }^{4}$ En el texto he optado por utilizar la forma castellanizada de los términos hebreos cuando existe (Torá, halajá, Janucá) y la forma más habitual en los demás casos, prescindiendo de signos diacríticos. Debe advertirse, sin embargo, que la h de haredim, hilonim, hodesh y haburah ha de pronunciarse como j, pues corresponde a la letra $\pi$. Igualmente se ha optado por no reduplicar la letra 1 pues en hebreo no existe el sonido que representa la 11.

${ }^{5}$ Masortim en plural y masortí en singular provienen de la palabra masora/masoret que significa tradición. Corresponde al judaísmo tradicional, también denominado conservador.

${ }^{6}$ En todas las estadísticas ofrecidas el porcentaje restante hasta completar el $100 \%$ corresponde a la categoría «otros».

${ }^{7}$ Por ejemplo, en Israel no existe entierro ni matrimonio civil. Aquellos que no quieran contraer matrimonio religioso deben hacerlo en el extranjero.

${ }^{8}$ Apartado 7.6, 344. Este estudio desglosa los porcentajes atendiendo a otros parámetros tales como la edad, estado civil, nivel de estudios, etc. Un dato significativo es el elevado número de judíos seculares entre los que han emigrado a Israel a partir de $1990(56,6 \%)$.

${ }^{9}$ Las dos primeras categorías quedarían incluidas en el judaísmo secular y las dos últimas en el religioso; si bien, aunque se produce un solapamiento entre las etiquetas de las dos, no se identifican completamente. 
ningún abuelo extranjero. La apertura y tolerancia de la sociedad estadounidense ha facilitado un alto grado de aceptación que favorece la asimilación y atenúa las diferencias entre lo judío y lo gentil como lo demuestra, por ejemplo, el elevado número de matrimonios mixtos, uno de los principales problemas a los que se enfrenta el judaísmo de este país (cf. infra).

También hay que tener en cuenta los movimientos migratorios. Tras el proceso de independencia de las colonias del norte de África (Marruecos, Argel, Túnez), los judíos de estos países emigraron a Francia, lo que contribuyó a un aumento significativo de la población judía de este país. Los judíos de países árabes como Irak o Yemen, que contaban con una larga tradición, se vieron obligados a trasladarse a Israel ante el deterioro de las condiciones de vida en sus países de origen. A los judíos de la antigua Unión Soviética se les permitió abandonar el país a finales de la década de los ochenta del siglo XX. Un millón de judíos soviéticos se trasladó a Israel, modificando el número y la composición de la población israelí de forma significativa ${ }^{10}$.

Por último, el flujo de judíos que se trasladaban a Israel desde la diáspora ha disminuido ${ }^{11}$ e incluso se constata un cierto aumento de judíos seculares que abandonan Israel para establecerse en Europa, donde esperan encontrar una sociedad laica que no esté condicionada por las exigencias del judaísmo religioso.

\subsection{LA SHOÁ}

En el judaísmo hay un antes y un después del Holocausto. La Shoá supuso la desaparición de numerosas comunidades judías y de su forma de vida. El mundo del shtetl que hablaba yidis en la Europa oriental y el de las comunidades sefardíes de Grecia y Bulgaria que usaban el ladino o judeoespañol desaparecieron. También es crucial la constatación de que el mundo había permanecido impasible ante una tragedia de dimensiones nunca vistas y de que, a partir de ahora, para sobrevivir los judíos solo podrán confiar en sus propias fuerzas. Surge así el mandato ético del «Nunca más» (el nuevo imperativo categórico de Adorno, el precepto 614 de Fackenheim). Al mismo tiempo, la Shoá tuvo un gran impacto sobre la filosofía y el pensamiento judío y sobre la forma de concebir la divinidad. Para Primo Levi, después de Auschwitz el problema de la fe se plantea en términos sencillos: «si Dios es Dios y, por tanto, omnipotente, entonces es culpable por haber permitido actuar a los asesinos; si, por el contrario, su poder es limitado, entonces no es Dios» ${ }^{12}$. El Holocausto obliga a abordar el problema del mal y del sufrimiento en el mundo, sobre todo el sufrimiento de los inocentes y de los niños. Todo ello cuestiona, desde la teodicea, el problema de

\footnotetext{
${ }^{10}$ La cifra corresponde a los datos de la emigración rusa en el periodo comprendido entre 1989 y 2011 e incluye en el cómputo los miembros no judíos de familias judías, cf. Della Pergola 2012, 29.

${ }^{11}$ Las cifras de inmigración sufrieron un retroceso hasta el punto de hablarse de una crisis de inmigración. En los último años dicha cifra se ha estabilizado, cf. DellaPergola 2013, 30. En todo caso hay que mencionar el repunte de la emigración desde Francia a partir del 2013 ante el aumento de ataques antisemitas.

12 En Wiesel 1996, 98.
} 
una divinidad injusta. Para resolver este problema teológico insalvable el premio Nobel de la Paz, Elie Wiesel, entiende que ya no podemos hablar a Dios, tan solo podemos hablar de Dios. Con esta afirmación intenta dar salida a un problema irresoluble.

\subsection{LA CREACIÓN DEL ESTADO DE ISRAEL}

La persecución y exterminio de los judíos por los nazis supuso el impulso definitivo para la creación del estado de Israel en 1948, como negación de la indefensión y debilidad de un pueblo condenado por el Holocausto a su completa desaparición. Casi dos mil años después los judíos vuelven a poseer un estado propio, el estado de los judíos como pueblo. A partir de este momento no tienen necesidad de vivir en otros países en situación de minoría. El judaísmo religioso ha adoptado posturas diversas ante esta nueva realidad. Hay quienes lo interpretan como un signo de escándalo, queriendo sustituir con sus propias manos la intervención de Dios. El sionismo religioso lo percibe como el inicio de la redención mesiánica y otros ven el cumplimiento de la posesión de la Tierra prometida por Dios a Abrahán, cuyas fronteras se justifican por los textos bíblicos. También hay quien lo considera un fenómeno sociopolítico sin significado religioso llevado a cabo por personas arreligiosas, o consideran que, sin ser irrelevante para la religión, no debe ser catalogado como positivo o negativo desde un punto de vista religioso.

Si bien para muchos sionistas es un hecho incomprensible, la diáspora continúa siendo una realidad. Muchos judíos no desean abandonar sus respectivos países, de los que se sienten parte integrante ${ }^{13}$. David J. Goldberg, un destacado rabino liberal ${ }^{14}$ de Londres sostiene en su libro This is not the way. Jews, Judaism and Israel (2012) que los judíos de la diáspora atesoran una experiencia de tolerancia y adaptación que es una valiosa aportación al judaísmo en general, especialmente ahora que existe el binomio estado de Israel-judaísmo y reivindica, además, que no todo lo que desde un punto de vista religioso se dice desde Israel, debe necesariamente coincidir con el sentir de los judíos que no viven allí.

\section{LA PLURALIDAD RELIGIOSA}

La modernidad o, mejor aún, la postmodernidad -como lo denominan algunos pensadores- es un desafio para cualquier religión. El progreso tecnológico, los cons-

\footnotetext{
${ }^{13}$ Tras el ataque contra una sinagoga en Copenhague el 15 de febrero de 2015, en el que murió una persona, el primer ministro israelí Benjamin Netanyahu ofreció a los judíos emigrar a Israel recordándoles que Israel es el hogar de todo judío. Los judíos daneses se lo agradecieron, pero decidieron permanecer en su país, tal y como recogen las palabras de Jeppe Juhl: «Nosotros somos daneses -somos judíos daneses, pero somos daneses-, y no es el terror lo que nos hará marcharnos». Recogido en el diario El Mundo con fecha de 17 de febrero de 2015.

${ }^{14}$ En Gran Bretaña el judaísmo conservador más radical recibe el nombre de liberal.
} 
tantes cambios que se producen en todos los ámbitos, la igualdad entre el hombre y la mujer, la ecología, la creciente importancia del individuo y la falta de certidumbres son, entre otros, factores de cambio que unidos a la falta de compromiso, la baja observancia religiosa y el concepto de religión en sentido amplio, originan situaciones desconocidas que demandan soluciones adecuadas a los nuevos tiempos. La modernidad exige tener una postura propia ante hechos y tradiciones que habían sido aceptados por las generaciones anteriores. Ahora, en cambio, cada individuo, desde la confianza en la razón humana y en la propia capacidad de discernir, debe posicionarse ante la teología ortodoxa judía, las costumbres tradicionales judías, el carácter divino de la Torá y la observancia de la halajá, la definición de la condición judía o repensar el papel de la mujer judía, entre otras cuestiones.

Como todas las religiones, el judaísmo no es estático ni monolítico, sino que en su dilatada historia ha experimentado cambios, evoluciones y tensiones. Algunas de las características del judaísmo actual se encuentran ya en el transcurso de su larga historia. En otras épocas, el judaísmo ha estado en contacto con diversos pueblos. El encuentro con culturas distintas, como por ejemplo la estancia en Babilonia durante el exilio o el contacto con el helenismo, fueron enormemente enriquecedores. Igualmente, la tensión entre asimilación y separación, entre universalismo y autosegregación se remonta a la época de Esdras con la prohibición de los matrimonios mixtos. En sentido contrario se encuentra la postura defendida en el libro de Rut, donde el contacto con los extranjeros es visto de forma positiva ${ }^{15}$. La riqueza y variedad de interpretaciones en el judaísmo contemporáneo evoca el final de la época del Segundo Templo periodo en el que el pluralismo religioso fue la característica más sobresaliente. Fariseos, esenios, saduceos, zelotas, la comunidad de Qumrán o los seguidores de Jesús de Nazaret mostraban su propia manera de concebir la religión.

Jacob Neusner ${ }^{16}$ distingue cuatro periodos en la religión judía: un primer periodo de diversidad desde el regreso del exilio hasta la destrucción del Segundo Templo, (500 a.e.c. -70 e.c.); un segundo periodo de definición (70-640 e.c.) con la conquista del islam en oriente y en el norte de África; un tercero de estabilidad (ca. 1800) y un cuarto que se prolonga hasta nuestros días, definido como un nuevo periodo de diversidad. Los orígenes de la pluralidad de este cuarto periodo se encuentran en las oportunidades económicas que ofrece la Revolución industrial y sobre todo, en la Ilustración y en la Revolución Francesa. La Ilustración trae consigo la preeminencia de la razón y el cuestionamiento crítico de la tradición. Con la Revolución Francesa se reconocen los derechos del individuo como ciudadano y no como miembro integrante de una confesión religiosa. Los judíos franceses son reconocidos como ciudadanos en tanto que individuos y no como judíos pertenecientes a un determinado colectivo religioso convirtiéndose en «ciudadanos franceses de religión mosaica» ${ }^{17}$.

\footnotetext{
15 Una extranjera, la moabita Rut, será la abuela del glorioso rey David.

${ }^{16}$ Neusner $2003^{2}, 15$.

${ }^{17}$ Este posicionamiento queda reflejado en la célebre declaración de Stanislas de Clermont-Tonnerre: «Il faut tout refuser aux juifs comme nation et tout accorder aux juifs comme individus».
} 
Por consiguiente, en este nuevo concepto de estado no tienen cabida las diversas comunidades ni hay lugar para cierto grado de autonomía o para la autosegregación de las mismas. Se inicia en Francia un proceso de emancipación para los judíos que, con distintos ritmos, se impondrá en toda Europa.

El deseo de integrarse en la sociedad, de formar parte de ella y de hacer propia la mentalidad burguesa y la cultura europea entran en contradicción con la creencia de que los judíos constituían una sociedad distinta y separada. Todo ello creó un clima propicio para el surgimiento del judaísmo reformista en la Alemania de finales del siglo XVIII ${ }^{18}$. Este proceso de integrar la tradición judía y las exigencias de los nuevos tiempos, de mantener una identidad religiosa judía $\mathrm{y}$, al mismo tiempo, formar parte de la sociedad, tendrá su máxima expresión en la figura de Mosé Mendelssohn. La modernización equivalía a hablar alemán, poner nombres alemanes a los hijos y vestirse con las ropas y el estilo propio de la burguesía.

En el ámbito religioso, el judaísmo se orienta hacia la fe personal y la interiorización. La observancia de la Ley se limita a los preceptos éticos. El decálogo prevalece sobre las minucias de las leyes relativas al sacrificio de los animales, los alimentos rituales y otras costumbres que distinguen a los judíos de los gentiles y se subraya la relevancia de la tradición profética en detrimento de la herencia talmúdica y rabínica. La acción social es vista como el medio dispuesto por Dios para transformar el mundo, asumiendo el deber de resolver las injusticias en la sociedad. Se acentuó el sentimiento de fraternidad común entre los judíos y se extendió al mundo gentil. Por otra parte el lenguaje religioso mantenía expresiones y referencias propias de otras épocas. Tras un lenguaje obsoleto, el significado de los símbolos litúrgicos se pierde y deja de tener sentido para los creyentes. Por ello, se buscan nuevas formas de expresión en la liturgia y el culto, en consonancia con los valores estéticos del momento. Se introdujeron cambios inspirados en el culto protestante como la utilización del alemán en los sermones, la música coral masculina y el órgano, y se eliminaron las expresiones arcaicas, particularistas o nacionalistas presentes en los libros de oración y en la profesión de fe.

La Reforma alentó la diversidad religiosa, el libre pensamiento y la autonomía personal. Pero de la mano de la emancipación y la asimilación también aparecieron nuevos peligros como los matrimonios mixtos, la apostasía y las conversiones al cristianismo. Ante el temor de que el judaísmo desapareciera, surge la nueva ortodoxia. Los seguidores de esta corriente se consideran los verdaderos continuadores, testigos fieles de la tradición, cuya fiel observancia garantiza la supervivencia del judaísmo. Sostienen que el propósito de la vida no es alcanzar la felicidad, sino servir a Dios. La Torá ha sido revelada por Dios y, en tanto que ley divina, es inmutable. El judaísmo ortodoxo no se preocupa tanto de los contenidos como del cumplimiento de la halajá (ortopraxis). No hay lugar para una mente abierta a la crítica bíblica ni a un análisis histórico del Talmud. Para la ortodoxia no hay nada más que hacer que continuar la

\footnotetext{
${ }^{18}$ La reforma, al igual que la nueva ortodoxia y el judaísmo conservador surgieron en Alemania, pero experimentaron importantes desarrollos en Estados Unidos a partir del siglo XIX.
} 
corriente del judaísmo que se ha ido transmitiendo durante siglos, por lo que el Talmud sigue teniendo un papel fundamental.

Aquellos que consideraban que los cambios de la reforma habían ido demasiado lejos se escindieron para constituir el judaísmo conservador. Los fundamentos ideológicos se establecieron en la segunda mitad del siglo XIX en el seminario rabínico de Breslau (Alemania). Puesto que el judaísmo había sido una religión dinámica, también tendría que cambiar y desarrollarse en el presente y en el futuro, aunque de forma orgánica y responsable, y dentro de un sentido de fidelidad y de lealtad al pasado. El judaísmo conservador propugna una manera de estar abierto a los tiempos modernos y, a la vez, permanecer fiel a la Torá mosaica, conservando de esta manera el verdadero espíritu judío. Frente al judaísmo entendido como fe judía, adquiere relevancia también el concepto de judeidad (Jewishness), que abarca la condición de judío en el sentido de pueblo y cultura, es decir, su historia, literatura, lengua y costumbres judías. En la práctica esta rama es una postura intermedia entre el judaísmo ortodoxo y el reformista. Son más reacios a desviarse de la tradición que los reformistas y aceptan los hallazgos de la investigación bíblica moderna.

Para expresar las diferencias existentes entre los tres movimientos, se suele afirmar que si los fundamentos del judaísmo son Dios, la Torá y el pueblo judío, la reforma prioriza a Dios, la ortodoxia la Torá y el judaísmo conservador el pueblo judío.

Ya en el siglo XX surge el Reconstruccionismo, que se posiciona entre el judaísmo religioso y el judaísmo laico, entendiendo el judaísmo como una civilización que integra elementos de ambos. Para M. Kaplan, su fundador, el judaísmo no es solo una religión, es una civilización que nace de las experiencias históricas y sociales del pueblo judío. En ese sentido la religión es parte importante de dicha civilización, pero también lo son otros componentes no religiosos como el folclore, la ley, la música, el arte y demás manifestaciones culturales. Esta corriente concede un gran valor a la observancia pero interpreta que la autoridad de la práctica judía no deriva de Dios sino de su estatus histórico y de la expresión del deseo e identidad corporativa del pueblo. La sinagoga continuará siendo el centro de la comunidad judía, pero comprendiendo todos los aspectos de la vida comunitaria (centro social), no solo los religiosos.

Mediante el análisis de dos temas concretos ilustraré los distintos planteamientos de cada una de estas corrientes.

\subsection{LA OBSERVANCIA RELIGIOSA}

El cumplimiento o incumplimiento de las leyes halájicas es uno de los mayores dilemas con los que se enfrenta el judaísmo actual, hasta el punto de que se habla de una crisis de la ortopraxis. Para los ortodoxos la halajá es un elemento indispensable y entienden que el judaísmo que no reconozca su autoridad divina no es auténtico. Al atribuir a las leyes origen y sanción divina, no ha lugar a modificaciones o adaptaciones. La ley es una forma de amar a Dios y, por tanto, fundamentan su fe en la práctica de las normas y ritos. Seguir en cada detalle el modo de vida judío es un recordatorio 
de la especial relación existente entre Dios e Israel. Los preceptos no están al servicio del hombre, ni deben ser vistos en relación a las necesidades humanas, sino que están al servicio de Dios y, desde esta comprensión, no son un medio sino un fin en sí mismo.

Sin embargo, muchos judíos sintieron en el pasado y también en la actualidad el corsé de un legalismo que les asfixia, y que, en lugar de acercarles a Dios, acentúa la distancia con él. Para muchos es una carga, especialmente las leyes relativas al ayuno, pureza, normas dietéticas o la santificación del sábado. Cuestionan su origen y sentido, sobre todo en aquellas que son más rituales que éticas y que responden a necesidades, circunstancias o costumbres de otras épocas.

Para el judaísmo conservador la Torá es una recopilación de tradiciones originadas en diferentes épocas del antiguo Israel. Las leyes están inspiradas por Dios, pero también son resultado de la reflexión humana. Considera vinculante la tradición, pero tiene de ella una visión dinámica, que se opone a la percepción estática de la ortodoxia. Partiendo de esta premisa se sienten capacitados para adaptar e incluso rechazar algunas normas de la ley judía cuando entran en conflicto con el sentir moderno. El judaísmo reformista fue más allá al rechazar la halajá que no estuviera en conexión con el comportamiento ético, potenciando todo lo relacionado con la tradición profética y la justicia social. El Reconstruccionismo, por su parte, concede libertad y autonomía a cada comunidad judía para que decidan qué costumbres y ritos tienen sentido en la vida actual. Aunque las decisiones pueden coincidir con las de otras sensibilidades, el proceso utilizado y la diversidad de conclusiones son características propias de esta corriente.

\subsection{EL PAPEL DE LA MUJER}

En la tradición judía la mujer desempeña un papel secundario. Su misión se centra en el matrimonio y en la descendencia, en el cuidado de la familia y la transmisión de la fe y valores judíos a los hijos dentro del hogar.

El judaísmo ortodoxo estricto se ha mantenido fiel a esta línea. En realidad es una religión patriarcal, en la que el varón prevalece sobre la mujer ${ }^{19}$. Las mujeres judías no tienen las mismas obligaciones religiosas que los hombres. No tienen parte activa en la liturgia ni en la sinagoga, donde se les asigna un lugar separado, con frecuencia en el piso superior. No pueden leer en público la Torá, recitar el kaddish por el alma del padre difunto o formar parte del quorum necesario de 10 hombres (minyán) necesario para celebrar un acto público de culto. Maternidad y matrimonio continúan siendo el papel asignado a la mujer, cuyas principales virtudes son la modestia y el recato.

Pero a las mujeres no les basta el ámbito doméstico. Reclaman la igualdad de deberes y oportunidades así como el derecho a una vida propia que no esté necesaria-

\footnotetext{
${ }^{19}$ El apego a la tradición les lleva a no practicar el control de la natalidad y a continuar con la práctica de los matrimonios concertados.
} 
mente vinculada a la familia. La participación femenina en la sociedad ha cambiado y la mayoría de las mujeres trabajan fuera del hogar y deben compatibilizar los requerimientos de la vida laboral y familiar. A diferencia del judaísmo ortodoxo, la igualdad de género es la norma en judaísmo reformista, en el reconstruccionista, y está muy extendido en el conservador.

El deseo de las mujeres de participar en la vida religiosa en igualdad de condiciones logró que fueran aceptadas en los seminarios rabínicos para formarse y poder desempeñar la función de rabino o de cantor en la sinagoga. En 1972 se ordenó la primera mujer rabino en el judaísmo reformista y para el año 2000 se contaba con 200 mujeres rabino en EEUU, 10 en Gran Bretaña, 4 en Israel y 2 en Francia. En el judaísmo conservador la decisión de aceptar mujeres rabinos en la década de los 80 del siglo pasado fue muy controvertida y generó grandes tensiones hasta el punto de provocar una escisión dentro de esta rama del judaísmo ${ }^{20}$.

La equiparación entre hombres y mujeres ha permitido un mayor protagonismo de las mujeres en la liturgia con la celebración de ritos similares a los de los varones, como Bat mitzvá (ceremonia religiosa que celebra el momento en el que el individuo adquiere plena responsabilidad religiosa y legal como judío), creando ritos nuevos como Shalom bat, la ceremonia de bienvenida a la alianza de Israel de las recién nacidas, como contrapartida a la circuncisión de los varones, o la recuperación de la festividad de origen bíblico Rosh hodesh a la que se dota de un nuevo significado; un día en el que grupos de mujeres judías se reúnen para estudiar y orar juntas.

El movimiento feminista también ha dejado su impronta en la religión judía. Surge una teología feminista judía, al igual que sucede en el cristianismo, que denuncia el patriarcado y la superioridad del varón, reclama un lenguaje inclusivo también en las traducciones de la Biblia y rescata del olvido el protagonismo de las mujeres bíblicas $^{21}$.

De gran trascendencia es la vigencia de la halajá en relación a la mujer $\mathrm{y}$, de manera especial, en lo que afecta al divorcio y a la agunah ${ }^{22}$, normativa por la que se rige en estos y otros temas el estado de Israel. La legislación religiosa judía es discriminatoria y deja en situación de inferioridad a la mujer. Solo el varón tiene derecho a conceder el divorcio a la esposa, independientemente de los motivos que llevan a la mujer a solicitarlo. El matrimonio queda disuelto cuando el marido entrega a la mujer el acta de divorcio (get), pero ésta es una decisión del marido y no de un tribunal rabínico ${ }^{23}$. En relación a la agunah, existen situaciones especiales en las que

\footnotetext{
20 Sobre la ordenación femenina en el judaísmo véase Nadell 1998.

${ }^{21}$ Sobre la teología feminista judía remito a dos recientes trabajos de carácter panorámico: Plaskow 2015, 39s. y Baker 2015.

${ }^{22}$ El término agunah remite a la situación de la mujer que, estando casada legalmente con un hombre, no vive con él. Puede ser, por ejemplo, por ausencia física o enfermedad mental. También designa a la mujer cuyo marido se niega a concederle el divorcio.

${ }^{23}$ La película israelí Gett: el divorcio de Viviane Amsalem (2014), dirigida por Ronit Elkabetz y Shlomi Elkabetz, refleja con exactitud la indefensión a la que esta legislación puede someter a la mujer.
} 
el marido desaparece sin dejar rastro y sin que su muerte se pueda verificar ${ }^{24}$. Para la ley judía no existe presunción de muerte y, por consiguiente, se requiere que aparezca el cuerpo o que exista el testimonio de algún testigo directo fiable. De no ser así, la mujer permanece casada, se le impide volver a contraer matrimonio y cualquier hijo que conciba arrastrará la condición de mamzer ${ }^{25}$.

Con esta sucinta presentación panorámica ${ }^{26}$ se puede constatar la pluralidad existente en el judaísmo religioso. La ortodoxia se sitúa en el extremo más tradicional e inmovilista, mientras el judaísmo reformista o liberal se encuentra en sus antípodas. Entre ellos, el judaísmo conservador y numerosos matices intermedios.

La diferencia más notable se sitúa entre los ortodoxos y los no-ortodoxos. Los primeros presentan una mayor homogeneidad, aunque al margen de la fe y de las ceremonias rituales, también se perciben diferencias. En la actualidad se distingue en Israel entre los datiim (religiosos), observantes más abiertos a la modernidad, que se benefician de la educación secular y de los frutos de la cultura moderna, y los haredim, los más estrictos. Estos últimos limitan el contacto con todo lo que les resulta ajeno para mantener un estilo de vida halájico puro, por lo que viven en barrios propios, replegados en sí mismos y hacen todo lo posible para aumentar el peso de la halajá en las instituciones nacionales y en el ámbito público.

Frente a ellos, los movimientos modernistas judíos comparten entre sí un fuerte compromiso con lo que consideran creencias religiosas y valores espirituales centrales, con instituciones religiosas y prácticas del judaísmo. Comparten la idea de que la herencia tradicional debe ser interpretada y revisada a la luz de los nuevos conocimientos, los avances técnicos y los cambios sociales. Todos ellos profesan la creencia en un Dios único y compasivo, en la autoridad de las Escrituras y mantienen las instituciones de la sinagoga y los rabinos. Muchos son conservadores y cautos al hacer reformas, si bien dentro de cada movimiento hay extremos más o menos radicales. Sin embargo, se percibe cierto retorno a la tradición por parte del judaísmo reformista y es posible que las distancias entre reformistas, reconstruccionistas y conservadores se acorten.

\section{JUDAÍSMO SECULAR O LAICO}

A partir del siglo XIX se empieza a hablar de judaísmo no religioso:

En el laicismo judío había una posibilidad contradictoria de ser metafísicamente judío sin creer en Dios (un sinsentido lógico que los judíos occidentales

\footnotetext{
${ }^{24}$ Por ejemplo, desparecidos en catástrofes naturales o marineros que mueren ahogados, cuyos cuerpos no se pueden recuperar.

${ }^{25}$ Hijo ilegitimo nacido de una relación adúltera o fuera del matrimonio, que queda excluido de la comunidad de Israel y al que se le prohíbe casarse con un judío o judía.

${ }^{26} \mathrm{La}$ falta de espacio me impide abordar detalles y matices necesarios en un tema tan complejo. Remito, entre otros, a Neusner, Avwery-Peck, Green 2000, Neusner, Avwery-Peck- $2003^{2}$ y Trebolle 2005.
} 
habíamos logrado preservar), manteniendo la profundidad de la identidad sin la incómoda obligación de los rituales ${ }^{27}$.

Con este nombre se designa al judaísmo que se construye al margen de la religión y que reinterpreta el judaísmo y su esencia histórica en sentido secular. El término incluye tanto al indiferente ante el hecho religioso como al agnóstico y al ateo ${ }^{28}$. El ateísmo judío tiene sus raíces en la Haskalá o Ilustración judía, que compartió los sentimientos antirreligiosos y anticlericales de la Ilustración europea y del socialismo judío de la segunda mitad del siglo XIX. En este periodo los judíos se integran en movimientos anarquistas, socialistas y comunistas de marcado carácter político, movimientos cuyo objetivo último es la construcción de una sociedad radicalmente nueva en la que los judíos participarán como uno más. Surgen, principalmente, en Europa del este y con la emigración, difunden sus ideales en Europa occidental y América del Norte. Estos movimientos alimentaron el incipiente sionismo (Hibbat Sion) y las primeras migraciones a Palestina. La mayoría de los judíos que se trasladaron a Palestina hasta la segunda guerra mundial se consideraban ateos y judíos al mismo tiempo. Ante el creciente antisemitismo que rebrota en Europa y el auge de los nacionalismos tras la primera guerra mundial, se impulsa, bajo la dirección de Teodoro Herzl y los congresos sionistas mundiales, la creación de un hogar nacional para los judíos.

Los judíos seculares han elegido abandonar la creencia en Dios, pero no por ello rechazan su identidad judía o su vinculación con el pueblo judío ${ }^{29}$. Por el contrario, su compromiso se refleja en la solidaridad para con las causas judías como campañas de ayuda a los judíos soviéticos para emigrar a Israel, colaboración con organizaciones benéficas o financiación de instituciones educativas. Otros se implican en el ámbito de la cultura judía, estudiando yidis o escuchando música klezmer. La lucha contra el antisemitismo y preservar la memoria de la Shoá ${ }^{30}$ son otras formas de mostrar su sentido de pertenencia. Igualmente, la participación en la lucha por los derechos humanos se entiende como una forma de vivir las obligaciones éticas de su herencia judía, dado que la justicia es un valor esencial del judaísmo.

\footnotetext{
27 Birmajer 2001, 132.

${ }^{28}$ Al igual que en la diáspora también en Israel esta cuestión suscita gran interés. Entre la bibliografía en hebreo se pueden mencionar, entre otras, Schweid 1985, Malkin 2000, Cohn 2006 e Itzhaki 2011.

${ }^{29}$ Amos Oz y su hija Fania Oz-Salzberger se ven a sí mismos como judíos israelíes laicos: «Esta definición entraña varios significados. En primer lugar, no creemos en Dios. Segundo, el hebreo es nuestra lengua madre. Tercero, nuestra identidad judía no está impulsada por la fe. A lo largo de toda nuestra vida hemos sido lectores de textos judíos, en lengua hebrea y no hebrea; son nuestras puertas de acceso culturales e intelectuales al mundo. En nuestros cuerpos, sin embargo, no hay ningún hueso religioso. Cuarto, vivimos actualmente en un clima cultural -dentro del sector moderno y laico de la sociedad israelí- que cada vez más identifica el citar la Biblia, las referencias al Talmud, e incluso el simple interés en el pasado judío como una inclinación de tinte político, atávico en el mejor de los casos, y en el peor, nacionalista y triunfalista. Este actual alejamiento liberal de la mayor parte de los temas judíos obedece a algunas razones, algunas de ellas comprensibles; no obstante es una equivocación.» Oz y Oz-Salzberger 2014, 18s.

${ }^{30}$ Como la creación de museos y monumentos conmemorativos, la recuperación de testimonios de supervivientes, la reconstrucción de las vidas de las víctimas son algunas de las tareas que emprenden o la elaboración de programas educativos destinados a niños y adolescentes.
} 
Los judíos laicos defienden un judaísmo vinculado a la noción de civilización. En una conferencia, Amós Oz lo explicaba así:

El judaísmo es una civilización. Y una de las pocas civilizaciones que han dejado su huella en toda la humanidad. La religión es un elemento central en la civilización judía, tal vez incluso su origen, pero esa civilización no puede ser presentada como nada más que una religión. A partir de la fuente religiosa de esa civilización se desarrollaron manifestaciones espirituales que ampliaron la experiencia religiosa, la cambiaron, e incluso reaccionaron contra ella: lenguas, costumbres, estilos de vida, sensibilidades características (o tal vez debiera decirse sensibilidades que solían ser características), y literatura y arte e ideas y opiniones. Todo esto es judaísmo. La rebelión y la apostasía en nuestra historia, especialmente en las últimas generaciones, también son judaísmo. Es un extenso y abundante legado ${ }^{31}$.

Esta percepción va unida a una determinada cosmovisión en la que la justicia, la responsabilidad hacia el prójimo y la solidaridad son consideradas valores judíos. Un pasado común, una memoria colectiva y una tradición entendida como legado cultural, conforman los vínculos y el imaginario común que cohesionan el grupo.

\section{4. ¿QUIÉN ES JUDÍO?}

La complejidad de esta cuestión queda patente en las consideraciones que hace DellaPergola $(2013,10-14)$ sobre los criterios adoptados para elaborar su estudio sobre la población judía mundial en el año 2013. La figura 3 representa mediante un diagrama los diversos solapamientos.

DellaPergola distingue entre núcleo de población judía (core Jewish population) y población judía extensa, es decir, en sentido amplio (enlarged Jewish population). En la mayoría de los países de la diáspora el núcleo de población judía estaría formado por todos aquellos que, cuando se les pregunta en un estudio socio-demográfico, se identifican a sí mismos como judíos. También se incluye a los que son identificados como judíos por otro miembro del hogar y no profesan otra religión monoteísta. DellaPergola asume que esta definición es un tanto subjetiva y puede no coincidir necesariamente con la halajá o con otro tipo de definiciones, pero, además, no tiene en cuenta el compromiso personal ni el comportamiento con respecto a la religiosidad, creencias, conocimiento, afiliación a una comunidad, etc. Por consiguiente bajo la etiqueta núcleo de población judía se engloban los que se definen como judíos por religión; los que, sin estar interesados por la religión, se consideran judíos étnicamente o por otros criterios culturales; los que no se consideran judíos pero son descendientes de padres judíos y no se declaran seguidores de otra religión. A ellos se añaden los

\footnotetext{
${ }^{31}$ Op. cit., 185.
} 


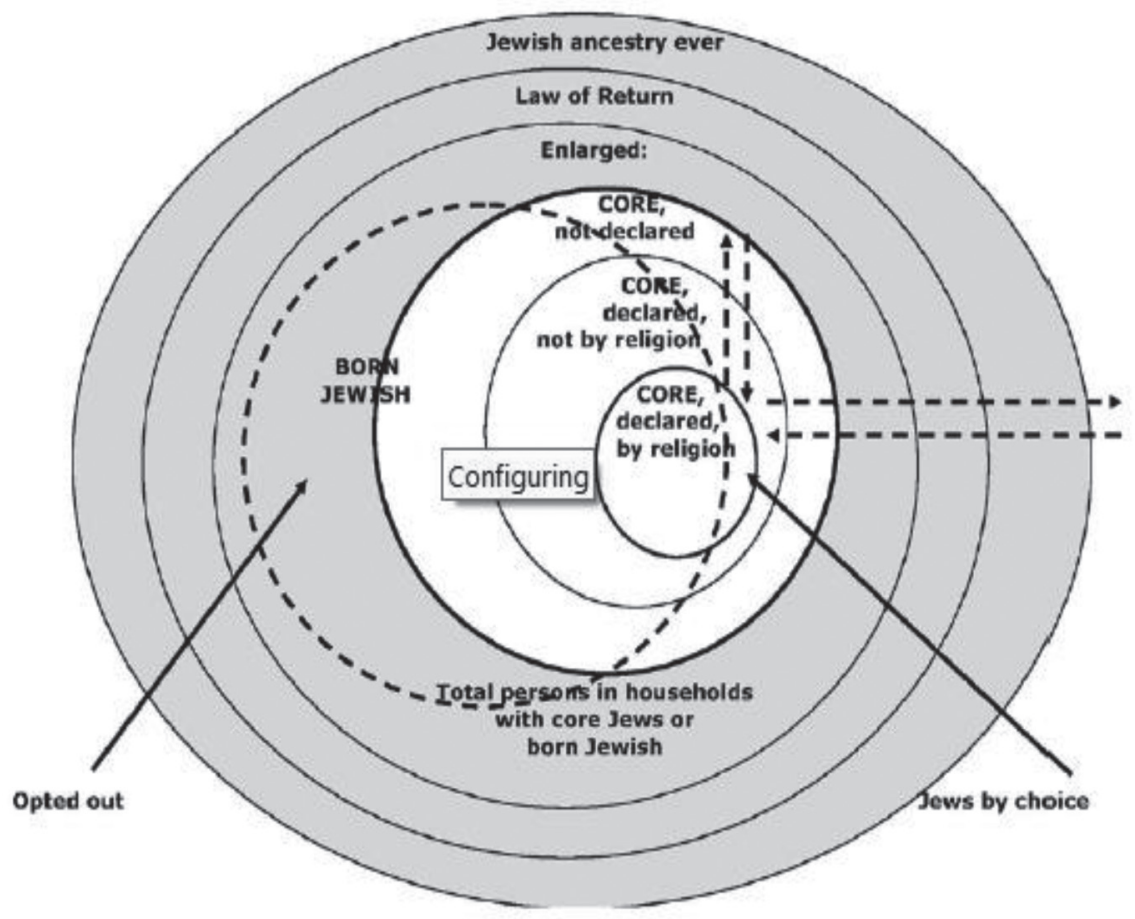

Figure 3. Configuring Contemporary Jewish Populations

conversos y los simpatizantes ${ }^{32}$. Se trata de un concepto integrador como él mismo reconoce: «The core concept offers an intentionally comprehensive and pragmatic approach reflecting the nature of many available demographic data sources» $(2013,11)$. En Israel, en cambio, el estatus personal depende del Ministerio del Interior a partir de criterios establecidos por las autoridades rabínicas de la corte suprema israelí. Por ello, en este país el núcleo de población judía no expresa una identidad subjetiva sino que refleja una normativa legal definida establecida a partir del origen judío o de la conversión. A diferencia de lo que sucede en la diáspora, los datos que se manejan no proceden de censos populares ni de encuestas donde el individuo puede decidir su respuesta en relación a cuestiones religiosas o identitarias, sino que son oficiales.

El concepto de población judía extensa incorpora al núcleo de población judía, a las personas no judías con antepasados judíos y a los miembros no judíos (esposas, hijos) de hogares donde hay judíos. Y también tiene en cuenta la Ley de Retorno que en Israel permite a los nuevos inmigrantes adquirir el derecho de ciudadanía. En dicha ley se recoge que es judía toda persona nacida de madre judía y que no tenga otra identidad religiosa o quien se haya convertido al judaísmo. Pero se dan casos

\footnotetext{
32 Serían aquellos que se definen como judíos sin haberse convertido.
} 
problemáticos como el de los falasha mura, etíopes con ancestros judíos que profesan la religión cristiana ${ }^{33}$ y que se encuentran en los límites de la definición identitaria ${ }^{34}$.

Dejando aparte las cuestiones demográficas, las dificultades para abordar este tema también se manifiestan en el título de una obra de compendio como es The Cambridge Guide of Jewish History, Religion and Culture ${ }^{35}$ donde el estudio de religión judía va de la mano de la historia y la cultura, una triada que se presenta inseparablemente unida. Desde la primera página de la introducción, sus editores, Judith Baskin y Kenneth Seeskin, abordan las dificultades para establecer en qué consiste la identidad judía y formulan las posibles respuestas en forma de preguntas: ¿una entidad nacional con una historia común basada en experiencias colectivas?, ¿una comunidad religiosa unida por creencias y ritos?, ¿un grupo étnico que comparte tradiciones culturales comunes?...

André Chouraqui, un conocido rabino francés, reflexiona así:

Según mi parecer, se puede ser judío de una manera global conectando con el mensaje, con el pueblo y con la tierra de Israel. Pero se lo puede ser también reconociendo uno de entre esos elementos: de hecho cada judío elige según su voluntad, el grado de fidelidad que él pretende conservar en relación al mensaje, al pueblo y a la tierra de Israel: los matices, hay que decirlo, son realmente innumerables. Hoy en día hay casi tantas maneras de ser judío como judíos hay ${ }^{36}$.

Esta diversidad responde a una decisión personal del individuo, como sostienen Amós Oz y Fania Oz-Salzberger:

¿Quién es judío? Todo el que esté luchando con la pregunta. «¿Quién es judío?» He aquí nuestra definición personal. Todo ser humano lo bastante loco como para llamarse judío, es judío. ¿Es un buen o un mal judío? Eso es algo que le corresponde decirlo al próximo judío ${ }^{37}$.

La identidad judía queda en manos de cada persona y, por tanto, habrá tantas identidades como judíos. Pero como se afirma al final del libro queda abierta la puerta a una gran subjetividad:

Y yo me veo a mí mismo como uno de los legítimos herederos. No un hijastro, o un desleal y desafiante hijo, ni un bastardo, sino un heredero según la ley. Y lo

\footnotetext{
${ }^{33}$ A diferencia del resto de los falashas que profesan la religión judía.

${ }^{34}$ DellaPergola cita en su estudio la definición empleada en el National Jewish Population Survey (NJPS) 2000-01: «a Jew is defined as a person whose religion is Judaism, OR whose religion is Jewish and something else, OR who has no religion and has at least one Jewish parent or a Jewish upbringing, OR who has a nonmonotheistic religion and has at least one Jewish parent or a Jewish upbringing» DellaPergola 2012, n.9, 64 . Para más detalles sobre el estudio de la demografía en relación al pueblo judío cf. DellaPergola 2002.

${ }^{35}$ Baskin, Seeskin 2010

${ }^{36}$ Daniélou, Chouraqui 2013, 62.

37 Oz, Oz-Salzberger 2014, 18.
} 
que se deduce de mi estatus como heredero, es lo que ciertamente os producirá un gran desasosiego. Porque se deduce que yo soy libre de decidir qué voy a escoger de esta gran herencia, qué voy a colocar en mi salón y qué voy a relegar al desván. [...] Es mi derecho a decidir qué me conviene y qué no. Lo que es importante y lo que es desdeñable y lo que voy a almacenar.» (op. cit., 185s.).

Al mismo tiempo, queda patente la dificultad de establecer fronteras que distingan al judío del no judío. Pero más allá de la postura de cada individuo ¿quién pone las etiquetas?, ¿quién se erige en juez y decide quién es judío y quién no lo es? Porque hay quienes se definen a sí mismos como judíos al tiempo que otros judíos les repudian como tales. Hay quienes aceptan la diversidad y quienes la rechazan porque entienden que solo su visión es la verdadera, la única interpretación posible. Un reflejo de ello es la tensión existente hoy en día entre Jerusalén y Tel Aviv y lo que cada una de ellas representa: la fidelidad a la tradición frente a la innovación y el cambio; el mundo religioso y el mundo secular.

La ortodoxia, siguiendo la halajá, establece quién es judío. La ley judía entiende que se es judío por nacimiento o por elección. En el primer caso se nace judío cuando los dos progenitores son judíos o, al menos, cuando lo es la madre. Dado el creciente aumento de los matrimonios mixtos en la diáspora, los judaísmos más abiertos también aceptan que se pueda transmitir por vía patrilineal. Es decir, que el progenitor varón sea judío y que el hijo o hija haya sido educado como tal. Esta es la postura del judaísmo reformista desde 1983 y también del reconstruccionismo. El judaísmo conservador presenta asimismo una disposición favorable, aunque aún no se ha pronunciado oficialmente al respecto.

Un no judío puede convertirse en judío mediante la conversión, ratificada por un tribunal de tres rabinos, que incluyera el estudio ${ }^{38}$, la inmersión en agua y en caso de ser varón la circuncisión. Algunos incluyen que debe pasar un tiempo con una familia judía o comunidad, y comprometerse a observar los mandamientos. Sin embargo, el Rabinato en Israel no considera válidas las conversiones realizadas en el seno del judaísmo conservador o reformista, por lo que hoy en día muchos miembros de la sinagoga conservadora y reformista que se sienten judíos, educan a sus hijos como judíos y son tenidos por tales en su comunidad, no son reconocidos por los ortodoxos.

Aunque cada judío se defina con una identidad propia resultado de la interacción de distintos elementos (pueblo, etnia, religión, cultura, memoria colectiva, la existencia del estado de Israel, la Shoá, etc.) y de la jerarquía de los mismos, todos tienen conciencia de pertenecer al pueblo de Israel, aunque no coincidan en su significado (Cohn-Sherbok 2001, 32). La cuestión es establecer la naturaleza de esos vínculos: religiosos, étnicos o culturales.

\footnotetext{
38 Sin embargo, esta no es la única interpretación. Apoyada en una antigua opinión rabínica, solo se requería un mínimo de estudio al converso que mostraba una firme convicción, ya que el proceso de aprendizaje se consideraba más efectivo si se llevaba a cabo dentro de la comunidad tras su aceptación (Lange 2000, 28).
} 


\section{REFLEXIONES FINALES}

El judaísmo tradicional basado en la ortopraxis, que ha permanecido básicamente inalterable durante siglos, se encuentra en un momento crucial. Como sucede ante cualquier desafío, corre el peligro de desaparecer, pero también puede salir reforzado, como ya sucedió en otras épocas. Mencionaré algunos de los principales retos a los que debe dar respuesta ${ }^{39}$ :

- La creciente brecha entre ortodoxos y no ortodoxos que puede desembocar en una escisión. Se requiere flexibilidad y creatividad para reforzar los elementos comunes frente a lo que les separa.

- Las tensiones entre una democracia secular y la imposición de las exigencias de los religiosos en la vida cotidiana en Israel.

- El creciente número de matrimonios mixtos en la diáspora. El rotundo rechazo a celebrar este tipo de matrimonios por parte del judaísmo ortodoxo y conservador contrastan con la actitud de apertura del judaísmo reformista y del reconstruccionismo, que celebran uniones entre judíos y miembros de otras confesiones religiosas. Acoger al cónyuge no judío y a los gentiles en general permite crear espacios de encuentro entre judíos y no judíos y fomentar relaciones fluidas entre ambos grupos.

- Durante muchos siglos la identidad judía se ha construido sobre la Torá que configuraba el estilo de vida judío a través del estudio y de la observancia. Ahora, en cambio, la identidad puede construirse al margen de la religión (luchando contra el antisemitismo, conservando viva la memoria de las víctimas de la Shoá, apoyando al estado de Israel, etc.). Sin embargo, estas formas de ser judío plantean el problema de la trasmisión del judaísmo a las futuras generaciones. Al construir su judaísmo desde los aspectos no religiosos carecen de los conocimientos que les permitan construir sus propias vidas judías y de saber por qué deberían hacerlo. Así, sin la presencia de las generaciones mayores, muchos no sabrían encender las velas de Janucá o celebrar el séder de Pascua ${ }^{40}$. Surge así el problema de la transmisión de las tradiciones a las futuras generaciones.

- La familia ha sido en el judaísmo el lugar de transmisión de las creencias, y tradiciones y valores judíos. Los cambios que está experimentando la familia tradicional con el surgimiento de nuevos tipos de familia y la disminución del tiempo compartido entre padres e hijos son situaciones nuevas que dificultan dicha transmisión.

- La búsqueda de un equilibrio entre el actual auge del individuo y el papel predominante de la comunidad en el pasado. En los EEUU, se sienten americanos y judíos a la vez. Ambas identidades comparten valores, pero mientras en la

\footnotetext{
39 Sobre el futuro del judaísmo pueden verse, entre otros, Lange 2000, 271-285, Benabassa, Attias 2002, Goldberg, Zaima 2002, 692-710 y Goldscheider 2010, 494-509.

${ }^{40}$ Cena ritual que se celebra en familia la primera noche de esta festividad en la que se lee el relato (Haggadah) de la esclavitud en Egipto y la posterior liberación (Éxodo 1-15).
} 
mentalidad americana el individualismo goza de un papel determinante, en el judaísmo son esenciales los conceptos de pueblo y de comunidad. La manera de articular esta tensión entre el yo y el nosotros será un elemento clave en el futuro del judaísmo ${ }^{41}$.

Cuestiones como qué es ser judío, qué me define como judío y me caracteriza como tal o dónde se encuentra mi sentido de pertenecía ya no se vinculan, al menos en la mayoría de los casos, con el grupo de origen o con la herencia recibida. La identidad se plantea como una decisión personal del individuo. Ser judío, por tanto, será el resultado de elegir ser judío. Una identidad que con frecuencia se define en términos negativos, descartando lo que no se es.

La identidad judía emerge como el resultado de aunar conceptos diversos como religión, ciudadanía, origen, posicionamiento político o identidad sexual. Así se puede ser judío, americano con ancestros polacos, hijo, esposo, padre y republicano. Hablamos, en este sentido, de identidades múltiples donde todos esos elementos configuran la realidad del individuo. Pero aún podemos avanzar un paso más. Cada persona, a lo largo de su vida, evoluciona y cambia su percepción del mundo y de sí mismo. Este aspecto, el de las identidades cambiantes, también ha de tenerse en cuenta.

Ante un mundo en incesante cambio, con un ritmo frenético, el judaísmo ortodoxo ofrece seguridades y genera certezas ${ }^{42}$. Al insistir en costumbres restrictivas antiguas se acentúa el sentido de pertenencia a una comunidad. La indumentaria se convierte en un signo diferenciador. Los varones llevan barba, tirabuzones, abrigos negros y sombreros. Las mujeres se visten con ropas modestas y manga larga y las casadas llevan la cabeza cubierta. Ello les permite reconocer al semejante y distinguir al diferente, al tiempo que es una manera de manifestar su presencia en la calle.

El relativismo, la falta de referentes seguros, la preponderancia del individuo frente a la colectividad, $-\mathrm{y}$ con ella la duda de si es posible mantenerse fiel a la propia fe en solitario, sin el apoyo de otros creyentes-, las repuestas a las necesidades espirituales al margen de las confesiones religiosas y el papel cada vez menor de la religión en la sociedad son rostros de un mundo complejo. Las interpretaciones que ofrece el judaísmo oscilan entre el inmovilismo de la ortodoxia que se blinda y aísla ante un mundo en constante cambio y la asimilación e integración que debilita los vínculos y atenúa el sentido de permanencia. Entre ambos extremos se sitúa una amplia gama de identidades.

\footnotetext{
${ }^{41}$ Cabe mencionar aquí el movimiento havurah que ha desarrollado comunidades de espiritualidad autónomas como alternativa a la sinagoga. Son grupos formados por un número reducido de personas que se reúnen para orar, celebrar el sábado, participar en comidas comunes, estudiar la Torá... En estos grupos existe un profundo sentido de intimidad, de igualdad entre sexos y se caracterizan por un estilo espontáneo, informal y creativo. Cf. Salkin 2000 , especialmente 565 ss. y Salkin $2003^{2}, 354$ ss.

${ }^{42}$ Hasta el punto que desde los años sesenta del siglo XX se está produciendo un fenómeno nuevo, los baaley teshubah. Ciertamente es minoritario, pero no por ello deja de ser significativo el retorno a la ortodoxia por parte de judíos que no habían sido educados en el judaísmo observante. En relación al «retorno a las raíces» como búsqueda de autenticidad, véase la sugerente interpretación de Solomon 1994, para quien se trata de innovación y de creación de una invención más que un proceso de redescubrimiento.
} 
Judaísmo y judeidad, tradición e innovación, religión y civilización, pasado y presente, Israel y la diáspora son claves en la comprensión del judaísmo actual. Es imprescindible conocer los procesos en los que está inmerso el judaísmo y las tensiones que afronta, no solo para entender la situación actual de esta religión, sino también en relación a otras religiones. El cristianismo y el islam también afrontan el desafío de la modernidad y se encuentran con problemas similares.

Tal vez sea esta una oportunidad única para crear una identidad judía; el momento de fijar unos mínimos que permitan establecer quién puede ser admitido y quién no, desde la tolerancia y la mutua aceptación ${ }^{43}$. En una época marcada por la incertidumbre, las religiones han de buscar el compromiso entre la tradición y la libertad del individuo, un equilibrio que encuentre espacios de consenso en el que integrar la diversidad. Ante esta pluralidad se requiere tolerancia y apertura para aceptar otros tipos de judaísmo, aunque sean muy distintos a lo que a lo largo de la historia se ha considerado como tal.

Cómo se ha dicho, la naturaleza del judaísmo hoy y la identidad judía son cuestiones «palpitantes», vivas. No podemos decir que exista un modelo considerado como la auténtica expresión del judaísmo, sino que las distintas interpretaciones coexisten en paralelo. Pero tal vez, como sostiene Neusner, nunca haya existido un judaísmo dominante hasta el punto de excluir a los demás:

But as their separate assumptions indicate, there is not no and there never has been a single Judaism that (speaking descriptively) dominated to the exclusion of all others. In modern times, we all recognize, there are a variety of Judaisms. Indeed, each Judaism, that is, each system, begins on its own and then -only thengoes back to the received documents in search of texts and proof-texts that can validate its role as «the Judaism» $»^{44}$.

\section{BIBLIOGRAFÍA}

\section{CBS, Statistical Abstract of Israel 2014}

http://www.cbs.gov.il/reader/shnaton/templ_shnaton_e.html?num_tab=st07_06x\&CYear=2014 [acceso 07.05.2015]

C. Baker, «Estudios bíblicos feministas judíos» en E. Schüssler Fiorenza, (ed.), La exégesis feminista del siglo XX. LBLM 20, Estella, 2015, pp. 163-178.

J. Baskin, K. Seeskin, The Cambridge Guide of Jewish History, Religion and Culture, Cambridge, 2010.

E. Benabassa, J. C. Attias, ¿Tienen futuro los judios?, Barcelona, 2002.

M. Birmajer, Historias de hombres casados, Madrid, 2001.

\footnotetext{
43 Solomon 1994, 97.
}

44 Neusner 2000, 579. 
H. H. Cohn: Being Jewish: Culture, Law, Religion, State, (en hebr.), Tel Aviv, 2006.

D. Cohn-Sherbok, Judaísmo, (trad. esp.), Madrid, 2001.

J. Daniélou, A. Chouraqui, A. Diálogo sobre los judíos, (trad. esp.), Pamplona, 2013.

S. DellaPergola, «Demography» en M. Goodman (ed.), The Oxford handbook of Jewish Studies, Oxford, 2002, pp. 797-823.

- Id., World Jewish Population, Current Jewish Population Reports 7, 2012, http://www. jewishdatabank.org/studies/downloadFile.cfm?FileID=2941 [acceso: 07.05.2015].

- Id., World Jewish Population, Current Jewish Population Reports 9, 2013, http://www. jewishdatabank.org/studies/downloadFile.cfm?FileID=3113 [acceso: 07.05.2015].

J. P. Denis, A. Fachon, El Atlas de las Religiones, Tres Cantos, 2010.

D. J. Goldberg, This is not the way. Jews, Judaism and Israel, London, 2012.

L. Goldberg, J. Zaima, «The Practice of Judaism in 21st Century U.S.A» en J. Neusner, A. J. Avery-Peck, W. S. Green (eds.), The Encyclopaedia of Judaism, Leiden, 2002, pp. 692- 710.

C. Goldscheider, «The Future of World Jewish Communities» en J. Baskin, K. Seeskin, The Cambridge Guide of Jewish History, Religion and Culture, Cambridge, 2010, pp. 494-509.

Y. Itzhaki, The Uncovered Head. Jewish Culture, New perspectives (trad. ingl.), Newark (USA), 2011.

N. Lange, de, El judaísmo (trad. esp.), Madrid, 2000.

Y. Malkin, What do Secular Jews believe (en hebr.), Tel Aviv, 2000.

P. S., Nadell, Women Who Would Be Rabbis: A History of Women's Ordination, 1889-1895, Boston, 1998.

J. Neusner, «Judaism, Defining of» en J. Neusner, A. J. Avery-Peck, W. S. Green (eds.), The Encyclopaedia of Judaism, Leiden, 2000, pp. 579-588.

— Id., «Defining Judaism» en J. Neusner, A. J. Avery-Peck (eds.), The Blackwell Companion to Judaism, Malden, $2003^{2}$, pp. 3-19.

J. Neusner, A. J. Avery-Peck, The Blackwell Companion to Judaism, Malden $2003^{2}$.

J. Neusner, A. J. Avery-Peck, W. S. Green (eds.), The Encyclopaedia of Judaism, Leiden, 2000.

J. Plaskow, «Movimiento e inicio de la investigación: los estudios bíblicos feministas durante la década de los setenta en los Estados Unidos» en E. Schüssler Fiorenza, (ed.), La exégesis feminista del siglo XX. LBLM 20, Estella, 2015, pp. 35-49.

A. Oz, F. Oz-Salzberger, Los judios y las palabras (trad. esp.), Madrid, 2014.

J. K. Salkin, «Judaism, Contemporary Expressions of; New Age Judaisms en J. Neusner, A. J. Avery-Peck, W. S. Green (eds.), The Encyclopaedia of Judaism, Leiden, 2000, pp. 563-579.

— Id., «New Age Judaism» en J. Neusner, A. J. Avery-Peck, The Blackwell Companion to Judaism, Malden $2003^{2}$, pp. 354-370.

N. Solomon, «Judaism in the New Europe: Discovery or invention?» en J. Weber, Jewish Identities in the New Europe, Oxford 1994, pp. 86-98.

E. Schweid, The Idea of Judaism as a Culture (en hebr.), Tel Aviv, 1985.

J. Trebolle Barrera, Los judios hoy, Córdoba, 2005.

E. Wiesel, Todos los torrentes van a la mar, Barcelona, 1996. 